\title{
Mating Market Dynamics, Sex-Ratio Imbalances, and Their Consequences
}

\author{
Mark Regnerus
}

Published online: 18 October 2012

(C) Springer Science+Business Media New York 2012

One of the most interesting and significant facts about coupled sexual behavior is the underlying market economy to it all. Once you peer into it, it's remarkable how it works. You might think it doesn't or shouldn't work this way when it comes to this most intimate and private of actions. But it does. And mating market dynamics continue to be consequential for how people live their lives, the options they're afforded, and the choices they make. At face value, the mating market concept is fairly elementary and certainly very old. Notable changes, however, have emerged in recent decades, and social scientists and social scientists are detecting their consequences.

\section{The Economics of Sex}

Sex is, among other things, a social exchange. There is a basic economics that typically precedes emerging-adult relationships and constitutes the setting in which they develop, end, or continue. In their 2004 Personality and Social Psychology Review article entitled "Sexual Economics," social psychologists Roy Baumeister and Kathleen Vohs explicate the important economic and market principles that characterize and shape the genesis of heterosexual relationships between unmarried adults. Each person gives the other person something of themselves. Although it might appear at face value to be the same something-intimate access to each other's body - there's often more going on than meets the eye. Men, on average, are more often drawn to the powerful physical pleasures of sex than women are. On

M. Regnerus $(\square)$

Department of Sociology, University of Texas at Austin,

1 University Station A1700,

Austin, TX 78712-0118, USA

e-mail: regnerus@prc.utexas.edu the other hand, physical pleasure is not often the sole motivator for women, and sometimes not even the primary motivator. More typically than men, women's interests also include receiving things like expressing and receiving love, attention, affirmation of desirability, reinforcing commitment, and relationship security. Don't get me wrong - men can appreciate each of those too, but they will tend to be secondary or tertiary reasons for pursuing sex.

Rest assured I know that women can and do like sex. But rest assured too that men tend to want sex more. As Baumeister articulates, men initiate sexual activity more often than women do. They fantasize about sex more often, masturbate more-arguably the purest measure of "excess" sexual drive - and are more sexually permissive than women. They connect romance to sex less often, and are generally slower to commitment. Whether they actually stray from their primary partnership or not, men direct far more mental time, effort, and attention toward other potential sexual partners than do women. Women, on the other hand, tend to be more malleable sexually. They are more likely to change their mind about sexual matters. Unmarried women tend to go without sexual activity for longer periods than unmarried men. We'll hear of twenty Anthony Weiners and Arnold Schwarzeneggers before we hear of one prominent woman politician who finds herself embroiled in a sex scandal of her own making. Indeed, none come readily to mind. In the world of sex, men and women are often quite different.

So men want more sex than women do, on average. In other words, in the heterosexual world women have what men want. Thus they possess something of considerable value to men, something that conceptually costs men to access. Historically, men have had to give something - most typically commitments or promises of the same - to get it. The very same thing, sex, isn't typically of value to women in quite the same way, as we pointed out above. As 
Baumeister and Vohs observe, women almost never pay men for sex. They just don't. That's not how they operate. (And that's probably, on balance, a good thing.)

When exactly does sex actually commence in a romantic relationship in which sex is consensual and men desire it more than women? The theory, as articulated by Baumeister and Vohs, provides a clear - though certainly contestedanswer: sex begins in relationships when women decide that it does. From both qualitative and quantitative assessments, this claim garners support. The correlation between sexual intentions and behaviors is much higher among women than among men. Men's level of agreement to invitations of casual sex with a (woman) stranger dwarfs that of the same in women. The bottom line is this: unmarried women are the sexual gatekeepers within their relationships.

The times have changed, however. Women have plenty of agency, opportunity, and success - more than ever before, and in multiple domains, including education and the labor market. Women can also more openly pursue sex for its own sake (and will typically succeed in their efforts). But I would assert that today's mating market is no less dominated by men's interests, and quite possibly more than in previous generations. I'm not suggesting that all men direct the course and outcomes of their relationships; absolutely not. But when I and others study the sexual relationships of young adults, it's obvious that the relationships and the norms and rules about them clearly favor men's interests, even while what men typically offer to women in return for sex is arguably diminishing. I'll spend the balance of this article describing how and why this is the case. I'll draw on some of my own survey analyses, as documented in Premarital Sex in America, but even more from recent studies conducted by other scholars. Explicating the sexual field is, of course, precarious territory, but I have no self-obvious political project herein. Rather, this is an assessment of where things stand and an argument about how we got here, with some space donated to speculations-educated guesses, really_about what happens next.

\section{A Bifurcating Mating Market}

Sex drive is thus the first of several imbalances that are worth noting. But in the domain of heterosexual sex, this particular imbalance is neither new nor terribly consequential for the wider sexual economy. It just means that for a very long time, men have been pursuing sex with women; sometimes they were successful, and sometimes they weren't.

Subsequent imbalances aren't nearly so old, and have been far more consequential. The advent of the hormonal birth control pill in 1960 is arguably the single-most powerful thing that has altered relationships between men and women in the past 50 years. The president of the National
Institute for Reproductive Health went so far as to suggest the Pill created the most profound change in human history. While such claims are impossible to confirm, suffice it to say that the advent of artificial hormonal contraception brought what economists call a technological "shock" to the social system, and the mating market in particular. To be sure, things didn't change overnight; no social change of significance ever does. Things didn't even change much over a few years, although certainly the pill began doing its job of regulating women's periods and preventing many pregnancies from occurring. Women could begin to have the number of children they wished to have. But over time the wide uptake of contraception has functioned to split what once was a relatively unified mating market into two quite distinct components. By "relatively unified" I simply mean that the majority of paired sexual activity among unmarried persons was conducted in and during the search for a mate, that is, someone to marry. Sex didn't necessarily mean marriage, but relationship security was often a value and a precursor to sex. In a survey of Americans conducted in 1970 - which interviewed over 3,000 adults, some of whom were born before $1900-54$ percent of the oldest men but only 7 percent of the oldest women reported having had premarital intercourse. With each successive cohort, those numbers rose, until 89 percent of men and 63 percent of women in the youngest cohort (born in 1940-49) reported premarital sex. This doesn't mean that our grandparents never messed around-whatever that meant to them. But in general, the average woman could and did count on seeing evidence of commitment before sex. If she didn'tand got pregnant-her family might step into the role of guarantor. Thus was born the shotgun wedding.

While the real gender gap in historical sexual behavior wasn't likely as profound as it appears - given strong social desirability concerns - it's a safe assumption that in the era of the Pill a far greater share of 18-year-old women are sexually active today than 50 or 100 years ago. Data from the National Longitudinal Study of Adolescent Health estimates that - by the mid-1990s - around two-thirds of 18year-old women had already had sex.

The mating market no longer functions in quite the manner it once did. In its place is a bifurcated market, split imperfectly into two overlapping bubbles - one for sex and one for marriage. (I will nevertheless refer to them most often as markets, since the two function like distinctive markets.) Since pregnancy can be easily prevented now, having sex and thinking about or committing to marry are two very different things today. Indeed, many young adults have no interest in marrying yet, or even getting serious, but have a strong interest in sex and romantic relationships short of marriage. The mating market bifurcation is not absolute, of course. Men and women can and do participate in both markets at the same time; indeed, most don't often perceive 
the market as bifurcated, and engage in sexual intercourse with varying degrees of hope or expectation that they will eventually marry their partner. The point remains, however, that the meanings and purposes of sexual behavior and relationships in the mating market are considerably more diverse than they once were.

Here again, the emergence of distinctive sex and marriage aspects of the mating market need not cause a problem, if comparable numbers of men and women tended to flock to each corner, and if they preferred to stay in one corner of the market or drifted over (or back) at comparable rates. But neither is true. There are more men in the sex market than women, and more women in the marriage market than men. And as people age, they tend to drift toward the marriage market - meaning they more intentionally wish to pursue marriage and intend their sexual behavior to serve that goal. But given their distinctive biological clocks and sexual preferences, men and women tend to drift from the sex market toward the marriage market at different paces, on average.

The lingo of online dating reinforces the reality of the bifurcated mating market and participants' difficulty in deciphering who is genuinely looking to mate and who's just looking to score. Persons write that they're interested in "NSA," meaning "no strings attached," or that they're "looking for fun," or for a "rendezvous." It's signaling that they're squarely in the sex market, and currently have limited interest in developing a committed romantic relationship. Persons in the marriage market tend to signal very different things, using phrases like "only serious inquiries, please" or "not into games," or "looking for an emotional connection" or "ready for a real relationship." This approach is far more common among women than men.

Men, on the other hand, display far higher interest in the sex market. Indeed, I noted in Premarital Sex in America that on a random Sunday evening in December 2009, I logged on to Austin's Craigslist "personals" site and tallied men's invitations for women to have casual sex with them and compared them with women's invitations to men for the same. A total of 166 invitations had been posted by men that day to women (and an additional 73 by men to other men); a mere three invitations to men for casual sex were posted by women. A repeat of the same late on a Monday morning in June 2011 revealed 75 invitations posted by men to women (before noon) and 78 by men to other men. Six invitations had been made by women to men, and one by a woman seeking another woman. While such counts are hardly scientific, the contrasting numbers reinforce two sexual economics theses: (1) women are the gatekeepers - that is, they can have sex when they wish to-while men can only hope and ask for it; and (2) there's a bifurcated mating market and it's notably imbalanced in its gender representation.

\section{Sex-Ratio Imbalances and Their Consequences}

A sex ratio is simply how many men there are in a group or community, compared with how many women there are. It's a demographic and sociological characteristic of which most people have only the vaguest awareness, and a simple measure of gender imbalance. The "sex-ratio hypothesis" holds that an oversupply of unmarried women in a community or group gives men therein considerably more power in romantic and sexual relationships, which translates into lower levels of relationship commitment, less favorable treatment of women by men, and a more sexually permissive climate wherein women receive less in exchange for sex. David Schmitt, a psychologist of sexuality whose International Sexuality Description Project evaluated sexual behavior patterns in over 56 countries, describes how it works: "The reproductive systems of lust and attachment in humans appear designed to react to features of local ecology. . . . In cultures with more men than women, humans become more monogamous and oriented toward long-term mating. It seems doubtful that the brains of men and women have a different design across cultures. Instead, the human sexual brain is designed to functionally respond to local circumstances and activate the lust, love, and attachment systems differentially depending on ecological conditions."

Power within relationships - a central principle in the sex-ratio hypothesis - is determined not simply by gender or only by such things as inequalities in the social status or physical attractiveness of the partners but also by surrounding market realities. Most pertinent to the sex-ratio hypothesis is the level of a partner's dependency. All else being equal, the availability of attractive alternatives outside of the relationship yet inside the local market tends to reduce an individual's dependency and result in lower levels of commitment to and investment in a relationship. Alternatives to the relationship are more readily available in markets where there is an oversupply of the opposite sex. In other words, if the sex market has more men than women in it - and it definitely does - then women can be more selective therein. Unfortunately, the very reason there are fewer women in the sex market is because most women tend to prefer (and are more apt to enjoy) sex in stable, committed, romantic relationships. Women's greater representation in the marriage market, on the other hand, allows men therein to be more selective, patient, cautious, and insist on sexual experience with marriage-minded women before committing, a position of maximizing rewards while paying limited costs. To women, it can appear that men are being "commitment-phobic." Thus it shouldn't surprise us that the median age at first marriage in the United States continues to rise, and that the share of Americans between the ages of 25-34 years old who are married is continuing to drop (10 percent over the past decade). While there are several factors that contribute 
to each trend, the sex-ratio imbalance in a bifurcated mating market is certainly one of them.

Indeed, data analyses of 117 countries suggest that those with higher overall sex ratios (that is, more men) have higher marriage rates and lower rates of child-bearing outside of marriage. Even teen-pregnancy rates are higher where men are scarce, given the logic that an oversupply of women leads to a more sexually permissive culture. (Remember, this occurs not because women are more permissive but because men are.)

The sex-ratio imbalance in American colleges and universities today is dramatic: 57 percent of students are women and only 43 percent are men. In 1947 there were more than twice as many men on campus as women ( 245 men for every 100 women). That significant gap dwindled until 1980, when women began outnumbering men in attending college. When there are considerably more women on campus than men, sex-ratio theory suggests it makes romantic relationships more difficult for women to navigate successfully. Is it true? In an article which appeared in The Sociological Quarterly, Jeremy Uecker and I matched campus data on sex-ratio imbalances in enrollment with data from the College Women's Study-collected by my late colleague Norval Glenn - in order to assess the independent effects of sex ratios on women's attitudes and actions about dating. We found that women on campuses where they comprise a higher proportion of the student body exhibit certain behaviors: they express more negative appraisals of men on campus; they hold more pessimistic views of their own romantic relationships; they go on fewer dates; and they have a lower likelihood of having a boyfriend (or having had one since entering college). Moreover, while having a boyfriend is understandably the best predictor of having had sex in the past month, we found that recent sex is more common - with or without a boyfriend - in colleges and universities that have a higher share of women. Conversely, virginity is far more common where women comprise a smaller share of the student body, controlling for a variety of individual and campus characteristics (like class standing, race, church attendance, conservative attitudes about sex, region of the country, campus-enrollment size, the university's academic exclusivity, the presence of Greek life, and whether it's a Christian college or not). After we take all of those into consideration, sex ratio still matters.

Other studies reinforce these conclusions. Emerging analyses from the National Longitudinal Study of Freshmen reveals that women are more likely to have sex during their freshman year on campuses where there are more women, independent of their sexual behavior prior to arriving on campus and a variety of other factors. As a result of campus sex-ratio imbalances, lots of women now find themselves in relationships with men that aren't in college at all, creating an awkward-and typically temporary-sexual relationship of imbalanced future directions.

The sexual effects of sex-ratio imbalances are not just a college phenomenon, either. Using data from high-school relationships in the National Longitudinal Study of Adolescent Health, economists found that in schools in which boys were relatively scarce, girls were more likely to agree to sexual relations than in schools were the sex ratio was not imbalanced. This, the authors argue, is because of girls' "matching concerns," that is, being worried that you won't have a boyfriend if you don't have sex with him. One of the reasons this study stands out is because, unlike in college, the sex-ratio imbalance in high schools isn't nearly so remarkable. To what do the authors attribute this? "That men and women value sex differently suggests that changes in sexual behavior may have different welfare effects for men than for women. Further, when gender ratios tilt such that men become a minority - as is the case on many college campuses - women are more likely to engage in sex conditional on forming a relationship, sacrificing their preferred relationship terms for a higher probability of matching."

Same story, multiple datasets: suffice it to say that there's something powerful going on here. Changes in American sexual norms have come about not simply because younger Americans have decided to think differently about sex, relationships, and the timing of marriage today, but because the traditional mating market has witnessed a massive reorganization in the past 60 years. This reorganization was made possible by the decoupling of sex from committed relationships - an unintended legacy, I would assert, of improved fertility control. The Pill created the single largest sustained drop in the "price" of sex that humans have ever witnessed.

For some Americans, however, corrosive sex-ratio imbalances aren't new, and have little to do with the Pill. Stanford Law professor Rick Banks identifies the acute sex-ratio imbalance in African American communities-a "man shortage" due in part to disproportionate incarceration rates - as contributing profoundly to a flight from marriage among them. It's not that African American women don't wish to marry, he asserts. They do. African American women have been considerably more successful in higher education and the labor force than their male counterparts of late. This has created, he argues, an impossible romantic environment for women: the least-employable men aren't marriage material. The most successful men, on the other hand, are in no hurry to marry because they clearly recognize their optimal market position. "Deviant" values about sex or marriage are not to blame, Banks asserts.

Why are more men than women of all races, classes, and occupational statuses content to remain in the sex market? They do so because they can. It is shrewd economics: "the market holds the key," claims Banks. The imbalanced sex 
ratio in the marriage market enables marriageable men to remain in the sex market, perhaps poaching marriagemarket inhabitants by feigning (or erroneously believing in) present or future possibilities of commitment. Many women can attest to such deception, and are themselves not immune to "playing games" with men or hoping to foster commitment by offering sex. Since the general mating market remains invisible, and the decoupling of the sex and marriage components of it seldom distinguished by the average person, women in the marriage market must often guess about the intentions of any particular man. In the era of online dating, however, accounts of men's and women's experiences with deception-social desirability bias-are rampant.

Given relatively stable sexual preferences, I assert that if women were more in charge of how their romantic relationships transpired - more in charge of the "pricing" negotiations around sex-we'd be seeing, on average, more impressive wooing efforts by men, fewer hook-ups, fewer premarital sexual partners, shorter cohabitations, and more marrying going on (and perhaps even at a slightly earlier age, too). In other words, the "price" of sex would be higher: it would cost men more to access it. Instead, none of these things are occurring. Not one. The price of sex is very low. How low? I note four proxy measures of it in Premarital Sex in America. The first and least helpful measure is simply the share of Americans who have sex before they get married; that's about $90-95$ percent. Thus the price is something less than the highest possible. It's not a terribly illuminating measure, however. There are much better ones, including the partner count of what are popularly referred to as "omega males," young men who-at face value - seem to have little to offer women in the way of resources or the promise thereof. If sex costs men something, then conceivably those with the least to offer should fare the worst. On the contrary: in the Add Health study, 22-year-old adult men who never enrolled in college - or who have dropped out - and are not presently employed full-time report having had 7.4 lifetime sexual partners, on average. Among 22-year-old highschool dropouts that figure rises to 8.6 partners. When contrasted with male college graduates, it's obvious that the economic resources or promise that men offer are of modest perceived value to potential sexual partners today. Such graduates report on average 4.9 lifetime partners, well below the numbers displayed by men who according to one indicator of resources - the standard of economic promisehave much less to offer a partner. Some suggest this altogether undermines the validity of the sexual economics model. On the contrary, I suspect it's simply an adaptation to the (low) perceived value of male resources in Pill-era sexual exchanges in a context where many young women are thriving and no longer need to marry.
Another measure is the speed with which relationships become sexual. The faster sex occurs, the less women are "charging" for it. When queried, 35 percent of young adult men's relationships become sexual within the first two weeks of the generation of the relationship, and a total of 48 percent within the first month. A final proxy measure of the price of sex is the share of men's relationships that they report as being "nonromantic," meaning they're not about romance or wooing, but simply about sex. "Friends with benefits," some call it. That figure, in the Add Health data, stood at 30 percent, meaning that three in ten relationships that men reported were primarily sexual, not romantic. If these data are analyzed by persons instead of by relationships, I can state that 20 percent of all sexually-active men between ages 18 and 23 have had sex with someone the first day they met her. If historically men were willing to work for sex - that is, earn the attentions of a potential partner by displaying commitment, life skills, and/or a promising trajectory - the modern man certainly doesn't have to. It's a different world, wherein the physical risks of sex have been dramatically lowered and the independent, economic trajectories of women dramatically raised, both a product - in part, directly and indirectly_of dramatic improvements in fertility control. Thus this new era has been great for women in terms of career options and labor force successes, but I assert that it is growing more challenging on them relationally. This is not the account of every young woman, for sure, but the route to marriage - something the vast majority of them assert as a goal - is more fraught with years and failed relationships than in the past. Once-familiar narratives about romance and marriage - how to date, falling in love, whom to marry, why, and when - are no longer widely affirmed. They remain ideals only in the mind, fast becoming out-ofstep with social reality.

\section{Why Care?}

It's not true, of course, that starry-eyed women are now simply being more efficiently duped or hoodwinked by skirt-chasing, commitment-phobic men. Not at all: many, many women don't mind this new sexual economy. Plenty of them like to spend some time in less-serious relationships before pursuing more significant commitments, and more than ever are eschewing mating entirely. Fertility control, a relatively recent phenomenon, is not only taken for granted, but many hold it as a human right. So why care about sex and marriage markets, ratios, and prices? People should be free to do whatever they want, right? Choice and options are sacred values, after all.

But truly free choice has largely disappeared, now that the general mating market has morphed into two distinctive components and given rise to vastly different power 
dynamics within each. It's no wonder that young-adult women tend to feel empowered by sex appeal-it is empowering in the market for shorter-term relationships. (Unfortunately, that's not the kind of relationship that most women report as optimal for their emotional and sexual satisfaction.) Yet as women age, many find themselves complaining about men's failures to commit or their anxiety about marrying before their fecundity diminishes. This makes sense, since women's market power is greater when they're a minority - that is, when they're younger and more open to sex market opportunities - than when they're in the majority, as they are when they're older and more deliberately interested in marriage. Any talk of the emerging power of cougars - that is, sexually-experienced older women -is primarily limited to the sex market, where they can compete with younger women by appealing to their own sexual experience and skills. Cougars have much less power in the marriage market. Age, experience with divorce, diminished fecundity, and the presence of other men's children curb the abilities of cougars to compete effectively in the marriage market. It's not that they cannot remarry; they can, and many do. The competition to do so, however, is taller, and men's selectivity greater.

In sum, what scholars and journalists have described as the "hook-up culture" that has emerged both on and off (and after) college campuses today, I assert, is less a result of sexual culture change than it is the product of the bifurcated mating market and the sex-ratio imbalances that have emerged therein. As a result of this imbalance, most unmarried men and women experience an extended series of sexual relationships and come to expect sex fairly promptly within them - either in step with or contrary to their personal preferences. It becomes very challenging for a minority to thwart this norm. Marriage-minded women, especially those who prefer to spend little or no time at all in the sex market, must search for a marital partner who's willing to pay a high price within a pool of people for whom the price of sex has declined considerably.

In the end, the sky is not falling. Most who wish to marry still do - especially the most educated - but the pathway to marriage is lengthening, and the journey there more circuitous. Marriage rates among 20- and 30-somethings will likely continue their slow skid, as the average age at first marriage continues to inch upward. Fertility concerns-already common - will increase apace. Nonmarital fertility has, and will probably continue to, climb. All of this is not, I assert, because the average woman prefers it this way.

\section{Further Reading}

Akerlof, G. A., Yellen, J. L., \& Katz, M. L. 1996. An Analysis of Outof-Wedlock Childbearing in the United States. The Quarterly Journal of Economics, 111, 277-317.

Armstrong, E. A., Hamilton, L., \& England, P. 2010. Is Hooking Up Bad for Young Women? Contexts, 9, 22-27.

Banks, R. R. 2011. Is Marriage for White People? How the African American Marriage Decline Affects Everyone. New York: Dutton.

Barber, N. 2000. On the Relationship between Country Sex Ratios and Teen Pregnancy Rates: A Replication. Cross-Cultural Research, 34, 26-37.

Baumeister, R. F. 2010. Is there Anything Good about Men? How Cultures Flourish by Exploiting Men. New York: Oxford University Press.

Baumeister, R. F., \& Vohs, K. 2004. Sexual Economics: Sex as Female Resource for Social Exchange in Heterosexual Interactions. Personality and Social Psychology Review, 8, 339-363.

Bogle, K. 2008. Hooking Up: Sex, Dating, and Relationships on Campus. New York: NYU Press.

Clark, R. D., \& Hatfield, E. 1989. Gender Differences in Receptivity to Sexual Offers. Journal of Psychology \& Human Sexuality, 2, 39-55.

Cohen, L. L., \& Shotland, R. L. 1996. Timing of First Sexual Intercourse in a Relationship: Expectations, Experiences, and Perceptions of Others. The Journal of Sex Research, 33, 291-299.

Ellingson, S., Laumann, E. O., Paik, A., \& Mahay, J. 2004. The Theory of Sex Markets. In E. O. Laumann, S. Ellingson, J. Mahay, A. Paik, \& Y. Youm (Eds.), The Sexual Organization of the City (pp. 3-38). Chicago: University of Chicago Press.

Guttentag, M., \& Secord, P. F. 1983. Too Many Women? The Sex Ratio Question. Beverly Hills: Sage.

Regnerus, M., \& Uecker, J. 2011. Premarital Sex in America: How Young Americans Meet, Mate, and Think about Marrying. New York: Oxford University Press.

Reichert, T. 2010. "Bitter Pill." First Things, May.

Schmitt, D. P. 2006. Short- and Long-term Mating Strategies: Additional Evolutionary Systems Relevant to Adolescent Sexuality. In A. C. Crouter \& A. Booth (Eds.), Romance and Sex in Adolescence and Emerging Adulthood: Risks and Opportunities (pp. 4147). Mahwah: Lawrence Erlbaum.

South, S. J., \& Trent, K. 1988. Sex Ratios and Women's Roles: A Cross-National Analysis. American Journal of Sociology, 93, 1096-1115.

Uecker, J., \& Regnerus, M. 2010. Bare Market: Campus Sex Ratios, Romantic Relationships, and Sexual Behavior. The Sociological Quarterly, 51, 408-435.

Mark Regnerus is an associate professor of sociology at the University of Texas and faculty research associate at the UT Population Research Center. He is author of Premarital Sex in America (Oxford University Press, 2011) and Forbidden Fruit: Sex and Religion in the Lives of American Teenagers (Oxford University Press, 2007). 